\title{
Experimental and analytical study about the compressive behavior of eps sandwich panels
}

\section{Estudio experimental y analítico sobre el comportamiento a compresión de paneles sandwich con eps}

\author{
G. Carbonari(*), S. H. P. Cavalaro ${ }^{(* *)}$, M. M. Cansario(**), A. Aguado(**)
}

Recepción / Received: 23-IV-12

Aceptación / Accepted: 25-I-13

\section{RESUMEN}

El presente estudio se centra en la caracterización del comportamiento de paneles tipo Sandwich con hormigón y EPS sometidos a cargas normales de compresión y teniendo en cuenta diferentes variables. Para ello, se han realizado campañas experimentales, cuyos resultados muestran que los aspectos geométricos, las propiedades de los materiales, la posición y la configuración del refuerzo influyen de manera significativa en la resistencia de los paneles. Asimismo se propone una formulación analítica para estimar la máxima carga resistida por los mismos. El estudio muestra que es especialmente importante definir la posición de las armaduras en la sección transversal ya que la excentricidad de las mismas reduce la resistencia a compresión de los paneles.

Palabras clave: panel sandwich; campaña experimental; compresión; formulación analítica; EPS.

\section{ABSTRACT}

This study presents a detailed characterization of the behavior of EPS sandwich panels subject to normal load taking into account several variables. For that, two experimental programs were performed, leading to the proposal of an analytical formulation to estimate the maximum load resisted. The results obtained show how the height of the panel, the material properties, the position and configuration of the reinforcement may affect the resistance of panels. Special attention should be given to the eccentric position of the reinforcement, which may reduce considerably the maximum load resisted. Some recommendations about the optimum placement of the reinforcement are proposed.

Keywords: sandwich panel; experimental campaign; compression; analytical formulation; EPS.

(*) State University of Londrina (Londrina, Paraná, Brasil).

(**) Universidad Politécnica de Cataluña (Barcelona, España).

Persona de contacto / Corresponding author: sergio.pialarissi@upc.edu 


\section{INTRODUCTION}

The construction system composed by sandwich panels is used in residential and industrial buildings due to the low self-weight and the optimization of the structural efficiency of the materials (1-3). In slabs and in columns, the cross section of these panels may be formed by two parallel concrete or mortar layers and an expanded polystyrene (EPS) layer in the middle $(2,4)$. To confer stability and to increase the out of plane bearing capacity, a series of steel connectors are placed between the different layers. In addition to that, a reinforcing steel mesh is embedded in each concrete layer as shown in Figure 1.

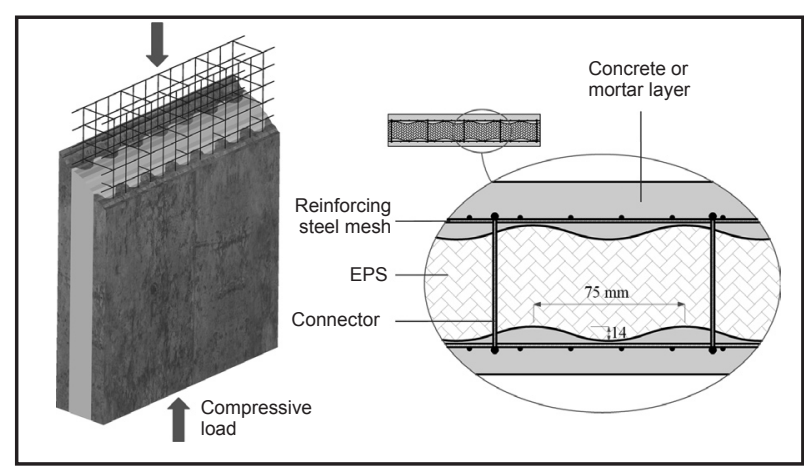

Figure 1. Isometric view and typical cross section of sandwich panel.

Although several papers focus on the flexural $(5,6)$ and the compressive (6-11) behavior of sandwich panels, most of the numerical simulation and analytical formulation found in the literature do not consider the eccentric position of the reinforcing mesh (12-14). Likewise, scarce information has been found about the influence of aspects such as the thickness of the layers or diameter and distribution of the steel connectors over the global strength of the panels (2). It is important to point out that the absence of a clear method to estimate this strength limits the application of the sandwich panels as a construction system (2).

Therefore, the main objective of the present study is to perform an extensive experimental characterization of the compressive behavior of sandwich panels with different supporting conditions and geometries. The data obtained in the first stage of the study is used to propose and to validate an analytical formulation to estimate the ultimate limit strength depending on the characteristics of the panel. The formulation proposed is then applied to evaluate the influence of the distance between connectors, the thickness of the layers and the position of the reinforcing steel mesh over the structural behavior of the panel.

The experimental study and the analysis performed in this paper represent a significant advance to the actual stateof-the-art about sandwich panels subject to compressive normal loads. It also offers a reasonable explanation for the structural behavior observed in practice.

\section{EXPERIMENTAL PROGRAMS}

Two experimental programs are proposed to evaluate the compressive behavior of panels. In the first of them, small-scale panels were tested in order to assess its local compressive strength. In the second of them, slender panels were tested to gage the global behavior of panels subject to higher lateral instability due to buckling.

In both cases, the sandwich panels tested are formed by two mortar layers with a wavy EPS layer between them. The EPS waves are $14 \mathrm{~mm}$ deep and $75 \mathrm{~mm}$ wide, being observed in a cross section perpendicular to the height of the panel and to the direction of compressive normal load applied (see Figure 1). The average thickness of the mortar layer is used to make reference to the panels in the experimental program and for calculation purposes in the structural simulations performed.

\subsection{Small-scale panels}

A total of 38 panels with different EPS thickness (from $40 \mathrm{~mm}$ to $120 \mathrm{~mm}$ ), mortar layer thickness (from $15 \mathrm{~mm}$ to $60 \mathrm{~mm}$ ), panel heights (from $300 \mathrm{~mm}$ to $777 \mathrm{~mm}$ ) and mortars mixes were tested. Table 1 shows the characteristics and the numbers of testes performed with each type of panel proposed. A detailed description of the panels and the mortar mixes used may be found in the work of Cansario (15). In this experimental program, the panels were identified by the letters SC and by a number that ranged from 1 to 26 .

Most of the panels present the same thickness for both mortar layers, except for panels SC8, SC9 and SC10, in which the effect of using different thicknesses for layers 1 and 2 was evaluated. The effect of variations on the EPS thickness (and consequently on the length of steel connectors) was also investigated.

In total 8 mortar mixes with Portland cement, lime, limestone sand, filler, plasticizers and air entraining admixtures were used to evaluate the repercussion of materials with different mechanical properties over the ultimate load. One mortar mix incorporated $1.2 \mathrm{~kg} / \mathrm{m}^{3}$ of plastic fibers (M4-PF1.2), whereas two mortar mixes included 0.6 and $3.0 \mathrm{~kg} / \mathrm{m}^{3}$ (M4-GF0.6 and M4-GF3.0) of Glass fibers. The production process for the mortars follows the UNE standards. The compressive strength of the mixes was measured in accordance with the standard UNE-EN 1015-11:2000 using cubic specimens. The results obtained are presented in parenthesis in the Table 1. 
Table 1. Characteristics of small-scale panels.

\begin{tabular}{|c|c|c|c|c|c|c|c|c|}
\hline \multirow{2}{*}{ Referen. } & \multirow{2}{*}{ Mortar } & \multicolumn{2}{|c|}{$\begin{array}{l}\text { Average mortar thickness } \\
(\mathrm{mm})\end{array}$} & \multirow{2}{*}{$\begin{array}{c}\text { EPS } \\
\text { thickness } \\
(\mathrm{mm})\end{array}$} & \multirow{2}{*}{$\begin{array}{l}\text { Connector } \\
\text { length }(\mathrm{mm})\end{array}$} & \multirow{2}{*}{$\begin{array}{l}\text { Width } \\
(\mathrm{mm})\end{array}$} & \multirow{2}{*}{$\begin{array}{l}\text { Height } \\
(\mathrm{mm})\end{array}$} & \multirow{2}{*}{$\begin{array}{l}\text { Number } \\
\text { of tests }\end{array}$} \\
\hline & & Layer 1 & Layer 2 & & & & & \\
\hline SC1 & \multirow{2}{*}{$\begin{array}{c}\mathrm{M} 1 \\
(4.60 \mathrm{MPa})\end{array}$} & 15.0 & 15.0 & 80 & 95 & 500 & 300 & 2 \\
\hline $\mathrm{SC} 2$ & & 15.0 & 15.0 & 120 & 135 & 500 & 300 & 2 \\
\hline $\mathrm{SC} 3$ & \multirow{8}{*}{$\begin{array}{c}\mathrm{M} 2 \\
(39.60 \mathrm{MPa})\end{array}$} & 15.0 & 15.0 & 80 & 95 & 500 & 300 & 2 \\
\hline SC4 & & 15.0 & 15.0 & 120 & 135 & 500 & 300 & 2 \\
\hline SC5 & & 15.0 & 15.0 & 160 & 175 & 500 & 300 & 2 \\
\hline SC6 & & 15.0 & 15.0 & 200 & 215 & 500 & 300 & 2 \\
\hline $\mathrm{SC} 7$ & & 15.0 & 15.0 & 240 & 255 & 500 & 300 & 2 \\
\hline $\mathrm{SC} 8$ & & 25.0 & 15.0 & 80 & 95 & 500 & 300 & 2 \\
\hline SC9 & & 25.0 & 15.0 & 120 & 135 & 500 & 300 & 2 \\
\hline SC10 & & 25.0 & 15.0 & 240 & 255 & 500 & 300 & 2 \\
\hline SC11 & \multirow{2}{*}{$\begin{array}{c}\mathrm{M} 3 \\
(17.15 \mathrm{MPa})\end{array}$} & 15.0 & 15.0 & 80 & 95 & 500 & 300 & 2 \\
\hline $\mathrm{SC} 12$ & & 15.0 & 15.0 & 120 & 135 & 500 & 300 & 2 \\
\hline $\mathrm{SC} 13$ & \multirow{4}{*}{$\begin{array}{c}\mathrm{M} 4 \\
(8.24 \mathrm{MPa})\end{array}$} & 58.5 & 58.5 & 80 & 95 & 555 & 475 & 1 \\
\hline SC14 & & 60.0 & 60.0 & 80 & 95 & 530 & 795 & 1 \\
\hline SC15 & & 60.0 & 60.0 & 80 & 95 & 545 & 483 & 1 \\
\hline SC16 & & 60.0 & 60.0 & 80 & 95 & 525 & 777 & 1 \\
\hline $\mathrm{SC} 17$ & \multirow{4}{*}{$\begin{array}{l}\mathrm{M} 4-\mathrm{FV} 3.0 \\
(9.12 \mathrm{MPa})\end{array}$} & 59.5 & 59.5 & 60 & 75 & 554 & 470 & 1 \\
\hline $\mathrm{SC} 18$ & & 60.0 & 60.0 & 60 & 75 & 530 & 770 & 1 \\
\hline SC19 & & 58.5 & 58.5 & 80 & 95 & 545 & 480 & 1 \\
\hline $\mathrm{SC} 20$ & & 59.0 & 59.0 & 80 & 95 & 530 & 782 & 1 \\
\hline $\mathrm{SC} 21$ & \multirow{2}{*}{$\begin{array}{l}\text { M4-FV0.6 } \\
(9.01 \mathrm{MPa})\end{array}$} & 58.5 & 58.5 & 60 & 75 & 550 & 467 & 1 \\
\hline $\mathrm{SC} 22$ & & 58.5 & 58.5 & 60 & 75 & 530 & 770 & 1 \\
\hline $\mathrm{SC} 23$ & \multirow{2}{*}{$\begin{array}{l}\text { M4-PF1.2 } \\
(8.51 \mathrm{MPa})\end{array}$} & 58.5 & 58.5 & 60 & 75 & 542 & 473 & 1 \\
\hline $\mathrm{SC} 24$ & & 58.5 & 58.5 & 60 & 75 & 521 & 776 & 1 \\
\hline $\mathrm{SC} 25$ & \multirow{2}{*}{$\begin{array}{c}\text { M5 } \\
(5.11 \mathrm{MPa})\end{array}$} & 22.5 & 22.5 & 40 & 55 & 550 & 477 & 1 \\
\hline SC26 & & 22.5 & 22.5 & 40 & 55 & 546 & 776 & 1 \\
\hline
\end{tabular}

A $75 \mathrm{~mm}$ square reinforcing mesh composed by galvanized steel bars with $3.4 \mathrm{~mm}$ of diameter was placed with a cover of $7.5 \mathrm{~mm}$ measured from the inner side of the mortar layer. Steel connectors with the same material and $3.0 \mathrm{~mm}$ of diameter were placed between the reinforcing meshes at every $225 \mathrm{~mm}$ on the width and at every 75 $\mathrm{mm}$ on the length of the panels. The main properties for the EPS and the reinforcing steel used in the experimental program are presented in Table 2.

The panels were cast in wooden molds with the mortar layer parallel to the ground. Initially, the mortar of the layer closest to the ground was poured into the molds.
Then, the steel mesh, the connectors and the EPS were placed (see Figure 2.a). Finally, the last mortar layer is cast and finished (see Figures 2.b, 2.c and 2.d).

The production and the tests of the panels SC1 to SC12 were conducted at the Consorci Lleidatà Control Laboratory (Lerida, Spain) using a hydraulic press as shown in Figure 3.a. The production and the tests of panels SC13 to SC26 were performed at the Technological Laboratory of Structures from UPC (Barcelona, Spain) also using a hydraulic press as shown in Figure 3.b. In both cases, steel plates were placed between the specimens and the press to assure a uniform load distribution.

Table 2. Main properties for the EPS and for the reinforcing steel used in panels.

\begin{tabular}{|l|c|c|c|c|c|}
\hline Material & Density $\left(\mathbf{k g} / \mathbf{m}^{\mathbf{3}}\right)$ & Elasticity modulus (MPa) & $\begin{array}{c}\text { Yield stress } \\
(\mathbf{M P a})\end{array}$ & $\begin{array}{c}\text { Compressive } \\
\text { strength (MPa) }\end{array}$ & Tensile strength (MPa) \\
\hline EPS & 25 & $5.9-7.2$ & - & - & $0.32-0.41$ \\
\hline Galvanized steel & 7850 & 210000 & 620 & 700 & 700 \\
\hline Steel B-500 S & 7850 & 210000 & 500 & 500 & 500 \\
\hline
\end{tabular}




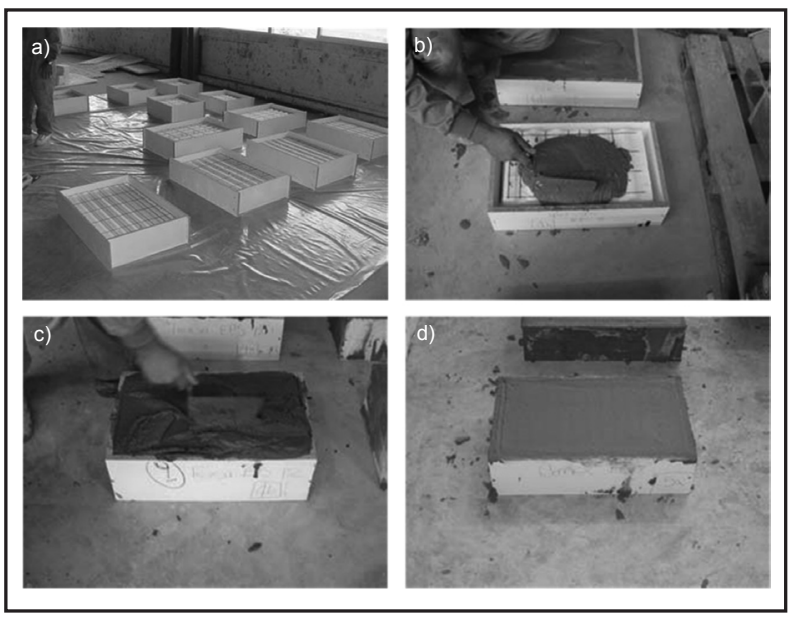

Figure 2. Production process of small-scale panels.

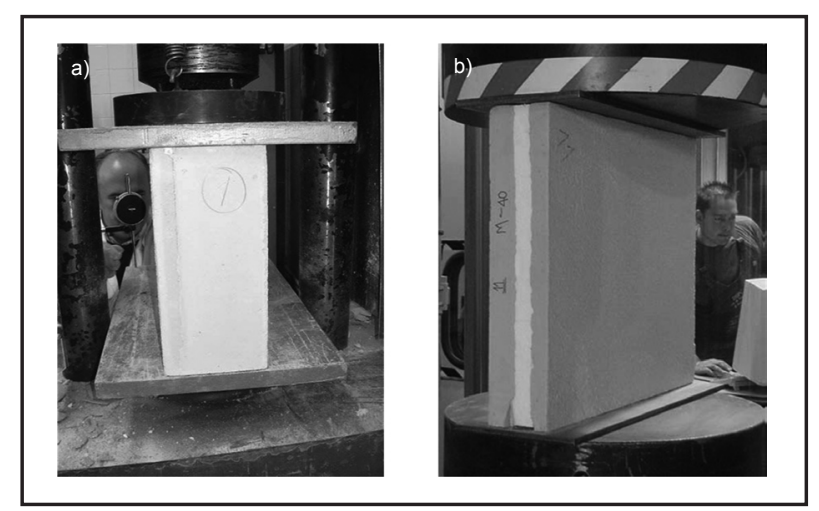

Figure 3. Tests performed at: a) the Consorci Lleidatà Control Laboratory and b) the Technological Laboratory of Structures from the UPC.

\subsection{Slender panels}

In the second experimental program one panels with $100 \mathrm{~mm}$ thick EPS (PMR-10) and one panel with $60 \mathrm{~mm}$ thick EPS (PMR-6) were tested. Both of them had $2.55 \mathrm{~m}$ of height and $0.90 \mathrm{~m}$ of length. Given the results obtained in the experimental program with small-scale panels, the thicknesses of the mortar layers were $40 \mathrm{~mm}$ and $50 \mathrm{~mm}$ each. The compressive strength of the mortar used was $25 \mathrm{MPa}$. As shown in Figure 4, a reinforcing steel hoop was cast in the upper and in the lower ends of the panel in order to reduce the incidence of local damages and to simulate the layout usually found in the joint between panels and slabs or foundations. (16)

The reinforcing mesh is composed by galvanized steel bars that on the vertical direction presented $3.4 \mathrm{~mm}$ of diameter and were placed at every $5 \mathrm{~cm}$ whereas on the horizontal direction presented $3.0 \mathrm{~mm}$ of diameter and were placed at every $15 \mathrm{~cm}$. In addition to that, 5 vertical steel bars of the type B-500 S with $6 \mathrm{~mm}$ of diameter were disposed coinciding with the position of the steel connectors in order to provide more stability to the reinforcement during the production of the panels. Galvanized steel connectors with $3.0 \mathrm{~mm}$ of diameter were spaced by $21.5 \mathrm{~cm}$ on the horizontal direction and by $15 \mathrm{~cm}$ on the vertical direction. Table 2 presents the material properties for the EPS and for the reinforcing steel used.

During the test, a group of jacks applied the compressive load to $3 \mathrm{~cm}$ thick steel plates that were in contact with the ends of the panels up to the failure. The tests were commissioned by the company Pamodin SL from the Instituto de Ciencias de la Construcción Eduardo Torroja. The results obtained are included in the context of the research project with the Universidad Politécnica de Cataluña (UPC) (CTT-UPC- 4791).

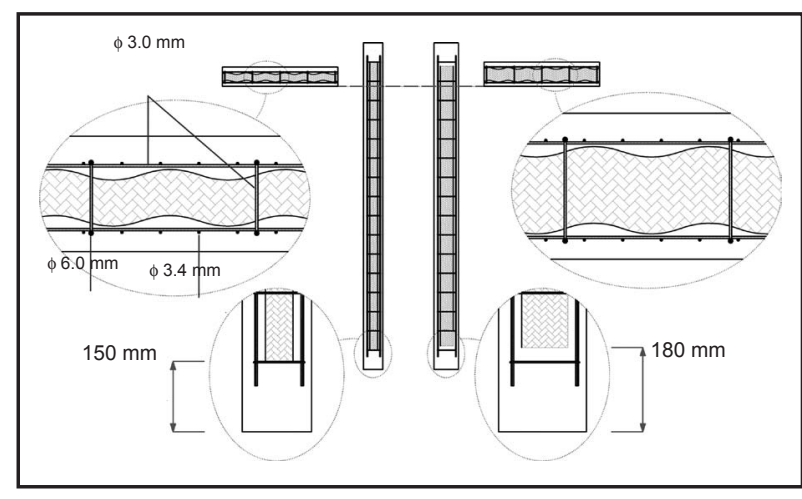

Figure 4. Longitudinal and transversal cross-sections of slender panels.

\section{RESULTS AND ANALYSIS}

\subsection{Small-scale panel}

During the test, a crack was generally observed parallel to the lateral surface of the panel. The crack opening increased as the compressive load was applied, leading to the failure of the panel, as shown in Figure 5. It is important to remark that such observations must be considered taking into account the small number of panels available with each configuration and the consequent high scattering of results verified in some cases.

Table 3 presents the maximum load measured for the panels tested. The influence of the EPS thickness (consequently of the connector length) may be observed through the analysis of results obtained for panels SC1 to SC12. In general, they show that the increase of the EPS thickness produces a decrease of the maximum load measured. Although in the case of panels with M1 mortar this is not noticeable, such outcome 
Table 3. Experimental and theoretical results for small-scale panels.

\begin{tabular}{|c|c|c|c|c|c|c|c|c|c|c|c|}
\hline \multirow{2}{*}{ Ref. } & \multirow{2}{*}{ Mortar } & \multicolumn{2}{|c|}{$\begin{array}{l}\text { Average mortar } \\
\text { thickness }(\mathrm{mm})\end{array}$} & \multirow{2}{*}{$\begin{array}{c}\text { EPS } \\
\text { thickness } \\
(\mathrm{mm})\end{array}$} & \multirow{2}{*}{$\begin{array}{l}\text { Width } \\
(\mathrm{mm})\end{array}$} & \multirow{2}{*}{$\begin{array}{l}\text { Height } \\
(\mathrm{mm})\end{array}$} & \multicolumn{3}{|c|}{$\begin{array}{l}\text { Experimental Pmax } \\
\qquad(\mathbf{k N})\end{array}$} & \multicolumn{2}{|c|}{$\begin{array}{c}\text { Theoretical Pmax } \\
(\mathrm{kN})\end{array}$} \\
\hline & & Layer 1 & Layer 2 & & & & $\begin{array}{c}\text { Spec. } \\
1\end{array}$ & $\begin{array}{c}\text { Spec. } \\
2\end{array}$ & Avar. & $\begin{array}{l}\text { Combined } \\
\text { compression- } \\
\text { bending }\end{array}$ & $\begin{array}{l}\text { Connector } \\
\text { buckling }\end{array}$ \\
\hline SC1 & \multirow{2}{*}{$\begin{array}{c}\mathrm{M} 1 \\
(4.60 \mathrm{MPa})\end{array}$} & 15.0 & 15.0 & 80 & 500 & 300 & 98.0 & 96.0 & 97.0 & 102 & 215 \\
\hline $\mathrm{SC} 2$ & & 15.0 & 15.0 & 120 & 500 & 300 & 111.0 & 91.0 & 101.0 & 104 & 164 \\
\hline $\mathrm{sC} 3$ & \multirow{8}{*}{$\begin{array}{c}\mathrm{M} 2 \\
(39.6 \mathrm{MPa})\end{array}$} & 15.0 & 15.0 & 80 & 500 & 300 & 493.0 & 468.0 & 480.5 & 520 & 502 \\
\hline SC4 & & 15.0 & 15.0 & 120 & 500 & 300 & 288.0 & 243.0 & 265.5 & 543 & 398 \\
\hline SC5 & & 15.0 & 15.0 & 160 & 500 & 300 & 419.0 & 352.0 & 385.5 & 543 & 330 \\
\hline SC6 & & 15.0 & 15.0 & 200 & 500 & 300 & 303.0 & 276.0 & 289.5 & 543 & 282 \\
\hline SC7 & & 15.0 & 15.0 & 240 & 500 & 300 & 293.0 & 237.0 & 265.0 & 543 & 246 \\
\hline SC8 & & 25.0 & 15.0 & 80 & 500 & 300 & 543.0 & 471.0 & 507.0 & 542 & 522 \\
\hline SC9 & & 25.0 & 15.0 & 120 & 500 & 300 & 253.0 & 228.0 & 240.5 & 567 & 414 \\
\hline SC10 & & 25.0 & 15.0 & 240 & 500 & 300 & 264.0 & - & 264.0 & 567 & 343 \\
\hline SC11 & \multirow{2}{*}{$\begin{array}{c}\mathrm{M} 3 \\
(17.15 \mathrm{MPa})\end{array}$} & 15.0 & 15.0 & 80 & 500 & 300 & 208.8 & 204.0 & 206.4 & 222 & 323 \\
\hline SC12 & & 15.0 & 15.0 & 120 & 500 & 300 & 191.0 & 152.0 & 171.5 & 229 & 251 \\
\hline $\mathrm{SC} 13$ & \multirow{4}{*}{$\begin{array}{c}\mathrm{M} 4 \\
(8.24 \mathrm{MPa})\end{array}$} & 58.5 & 58.5 & 80 & 555 & 475 & \multicolumn{3}{|c|}{732.0} & 613 & 512 \\
\hline SC14 & & 60.0 & 60.0 & 80 & 530 & 795 & \multicolumn{3}{|c|}{528.0} & 599 & 510 \\
\hline SC15 & & 60.0 & 60.0 & 80 & 545 & 483 & \multicolumn{3}{|c|}{802.0} & 615 & 502 \\
\hline SC16 & & 60.0 & 60.0 & 80 & 525 & 777 & \multicolumn{3}{|c|}{589.0} & 593 & 500 \\
\hline SC17 & \multirow{4}{*}{$\begin{array}{l}\text { M4-FV3.0 } \\
(9.12 \mathrm{MPa})\end{array}$} & 59.5 & 59.5 & 60 & 554 & 470 & \multicolumn{3}{|c|}{587.0} & 687 & 564 \\
\hline SC18 & & 60.0 & 60.0 & 60 & 530 & 770 & \multicolumn{3}{|c|}{672.0} & 663 & 542 \\
\hline SC19 & & 58.5 & 58.5 & 80 & 545 & 480 & \multicolumn{3}{|c|}{795.0} & 666 & 544 \\
\hline $\mathrm{SC} 20$ & & 59.0 & 59.0 & 80 & 530 & 782 & \multicolumn{3}{|c|}{723.0} & 653 & 532 \\
\hline SC21 & M4-FV0.6 & 58.5 & 58.5 & 60 & 550 & 467 & \multicolumn{3}{|c|}{652.0} & 664 & 543 \\
\hline $\mathrm{sc} 22$ & $(9.01 \mathrm{MPa})$ & 58.5 & 58.5 & 60 & 530 & 770 & \multicolumn{3}{|c|}{650.0} & 635 & 541 \\
\hline $\mathrm{sc} 23$ & M4-PF1.2 & 58.5 & 58.5 & 60 & 542 & 473 & \multicolumn{3}{|c|}{631.0} & 617 & 512 \\
\hline SC24 & $(8.51 \mathrm{MPa})$ & 58.5 & 58.5 & 60 & 521 & 776 & \multicolumn{3}{|c|}{691.0} & 594 & 510 \\
\hline $\mathrm{SC} 25$ & M5 & 22.5 & 22.5 & 40 & 550 & 477 & \multicolumn{3}{|c|}{131.0} & 174 & 126 \\
\hline SC26 & (5.11 MPa) & 22.5 & 22.5 & 40 & 546 & 776 & \multicolumn{3}{|c|}{132.0} & 173 & 124 \\
\hline
\end{tabular}

is evident in the case of panels with M2 and M3 mortars. In the former, the increase of the EPS thickness from $80 \mathrm{~mm}$ (in SC3 and SC8) to $240 \mathrm{~mm}$ (in SC7 and SC10) led to an average reduction of $44 \%$ in the maximum load. In the latter, the increase from $80 \mathrm{~mm}$ (SC11) to $120 \mathrm{~mm}$ (SC12) produced a reduction of $16,9 \%$ on the maximum load measured.

Table 3 also shows that, in panels with similar characteristics, the increase of the compressive strength of the mortar layer produces an increase of the maximum load resisted. In general, this effect was more evident for panels with smaller EPS thickness. For instance, in panels SC1, SC3 and SC11 (all with $80 \mathrm{~mm}$ EPS thickness) the increase of the mortar compressive strength from 4.6 $\mathrm{MPa}$ to $17.15 \mathrm{MPa}$ and to $39.6 \mathrm{MPa}$ led to an increase of $112 \%$ and $395 \%$ of the maximum load, respectively. On the other hand, in panels SC2, SC4 and SC12 (all with $120 \mathrm{~mm}$ EPS thickness) the same change of the mortar compressive strength led to an increase of $70 \%$ and $163 \%$ of the maximum load, respectively.

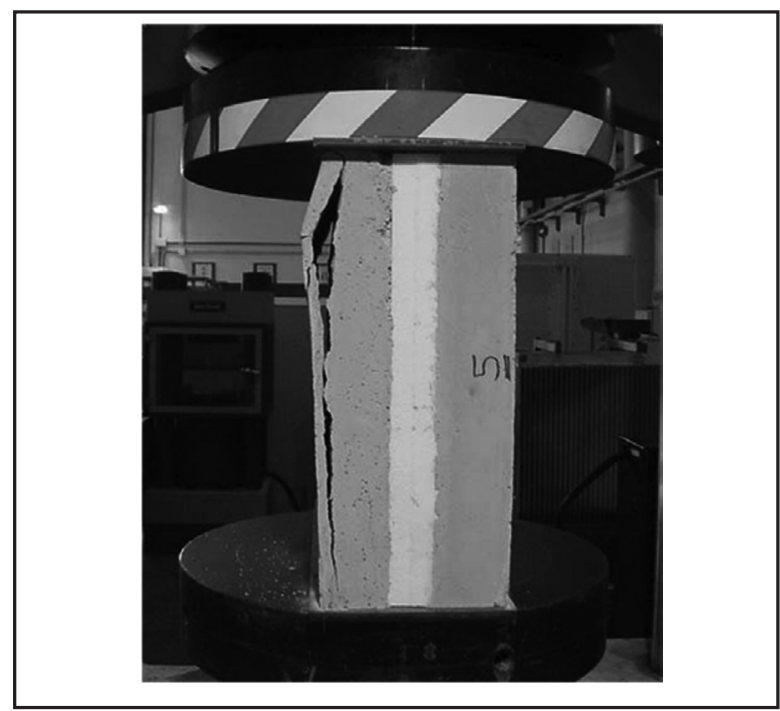

Figure 5. Typical panel failure. 
It was observed that the height of the panels may affect considerably the results obtained. In general, the increase of this dimension produces a considerable reduction of the maximum load. Such response may be attributed to the increase of the bending moment due to test imperfections and second order moments in higher panels. The only exceptions to this observation were found for panels cast with M4-PF1.2 and M4-FV3.0 mortar.

The use of different mortar layer thicknesses (15 and $25 \mathrm{~mm}$ ) in panels SC8, SC9 and SC10 did not cause any significant variation regarding the maximum load measured in the test of panels SC3, SC4 and SC7, which present the same thickness for both mortar layers (15 mm). Apparently, the cross section increase in the former does not affect the failure mechanism that is more dependent of the EPS thickness (length of the connectors) and the minimum mortar layer thickness.

The change of the glass fiber content from $0.6 \mathrm{~kg} / \mathrm{m}^{3}$ (panels SC17 and SC18) to $3.0 \mathrm{~kg} / \mathrm{m}^{3}$ did not show a clear influence over the test results. Likewise, no significant variation on the maximum load was observed between panels with glass fiber and with polyester fiber.

\subsection{Slender panels}

Table 4 shows the results in terms of the maximum load measured for each panel of the second experimental program. The typical failure observed was similar to that of the small-scale panels with a higher tendency to lateral instability. It was verified that the increase of the EPS thickness and of the length of the connectors led to a decrease of the maximum load measured. The increase from $60 \mathrm{~mm}$ to $100 \mathrm{~mm}$ on the EPS thickness produces a decrease of $9.4 \%$ in the maximum load. This confirms the trend already observed in the test with small-scale panels (section 3.1). Again, it is important to remark that such observation must be considered with caution given the very limited number of panels tested.

Table 4. Experimental results for slender panels.

\begin{tabular}{|c|c|c|c|c|c|}
\hline \multirow[t]{2}{*}{ Panel } & \multirow[t]{2}{*}{ Mortar } & \multicolumn{2}{|c|}{$\begin{array}{l}\text { Average mortar } \\
\text { thickness }(\mathrm{mm})\end{array}$} & \multirow{2}{*}{$\begin{array}{c}\text { EPS } \\
\text { thickness } \\
(\mathbf{m m})\end{array}$} & \multirow{2}{*}{$\begin{array}{c}\text { Pmax } \\
\text { measuered } \\
(\mathrm{kN})\end{array}$} \\
\hline & & Layer 1 & Layer 2 & & \\
\hline PMR-60 & \multirow{2}{*}{$\begin{array}{c}\mathrm{M}-6 \\
(25 \\
\mathrm{MPa})\end{array}$} & 50 & 40 & 60 & 530 \\
\hline PMR-100 & & 50 & 40 & 100 & 480 \\
\hline
\end{tabular}

\section{THEORETICAL ANALYSIS}

\subsection{Conceptual basis}

The maximum load estimated using centered pure compression of the panels does not explain either the maximum load measured or its variation in the experimental program. This indicates the existence of other mechanisms that may affect the resistance of the panels, thus leading to smaller maximum loads.

To understand a possible explanation for this outcome, consider the behavior of only one of the mortar layers. In theory, the high stiffness of the steel plates and the plates of the press induce a uniform deformation of the layer. Under such condition, the deformation experienced by the mortar and the reinforcing steel should be the same. Given the higher elastic modulus of the steel, the stress acting at this material could be bigger than the stress acting at the mortar. If the reinforcing steel mesh is not centered, it will induce a load concentration at points located apart from the geometrical gravity centerline of the layer " $G$ " (calculated considering only the geometry of the cross-section). Consequently, the theoretical resultant load at the layer would be applied with an eccentricity " $e$ " as shown in Figure 6.

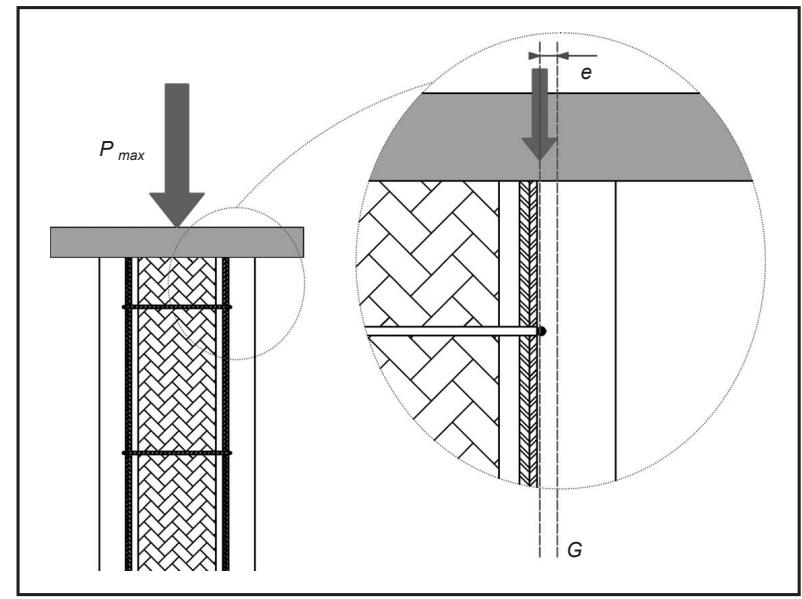

Figure 6. Eccentric load applied to each mortar layer.

This eccentricity might be related with a bending moment and a lateral deflection, which induce a nonuniform stress distribution. In this context, the bending moment and the lateral deflection of the mortar layer should increase with the load, triggering two possible failure mechanisms.

In the first one of them, the failure is caused by a combined compression-flexion state that reaches the limit resistant capacity of the mortar layer (see Figure 7.a). In the second of them, the failure happens due to lateral instability when the buckling of connectors occurs (see Figure 7.b). In both cases, a high stress concentration is observed in the outer side of the mortar layers, thus generating the cracks shown in Figure 5. The following sections present the analytical deduction of the equations to estimate the maximum load resisted by the panels for the failure mechanisms described previously. 


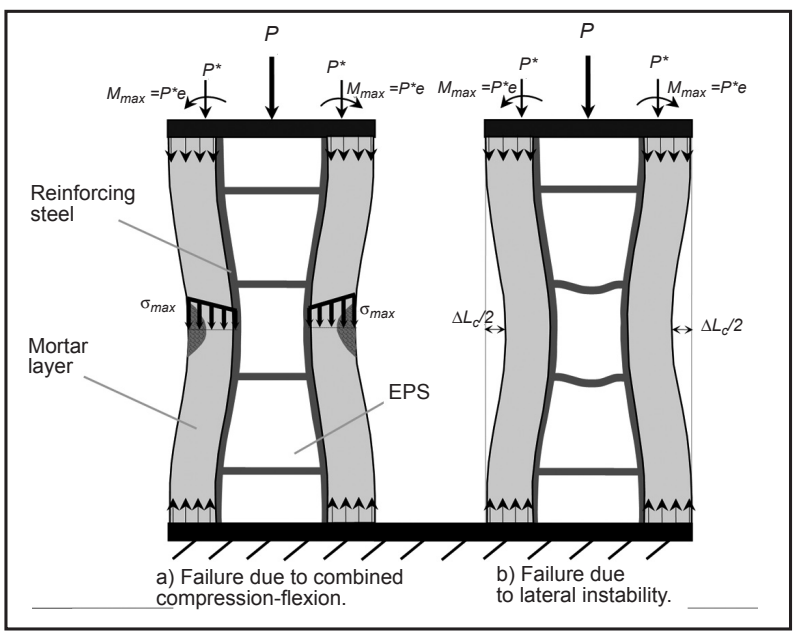

Figure 7. Failure mechanisms of panels.

\subsubsection{Failure due to combined flexion-compression}

The maximum bending moment $\mathrm{M}_{\max }[1]$ and the maximum lateral displacement $\mathrm{v}_{\max }$ [2] at the center of the panel may be obtained using the Euler hypothesis (17) for a slab subjected to a load P* with an eccentricity " $e$ ". In these equations, the buckling height $L_{\text {buckling }}$ is considered as half of the actual panel length whereas $E_{m}$ and $I_{\text {layer }}$ represent the mortar elasticity modulus and the moment of inertia for a single mortar layer.

$$
\begin{gathered}
M_{\max }=P^{*} e\left[\sec \left(\frac{\mathrm{L}_{\text {buckling }}}{2} \sqrt{\frac{\mathrm{P}^{*}}{\mathrm{E}_{\mathrm{m} \text { layer }}}}\right)\right] \\
v_{\max }=e\left[\sec \left(\frac{\mathrm{L}_{\text {buckling }}}{2} \sqrt{\frac{\mathrm{P}^{*}}{\mathrm{E}_{\mathrm{m} \mathrm{I}_{\text {layer }}}}}\right)-1\right]
\end{gathered}
$$

The maximum stress acting at the mortar layer may be obtained using the maximum bending moment [1] and the classical resistance of materials equation to estimate the stresses due to combined flexion-compression (17). This is represented in equation [3] in which $A_{\text {eq }}$ represents the cross-section of the mortar layer and $r_{\text {layer }}$ is given by equation [4].

$$
\begin{gathered}
\sigma_{\max }=\frac{\mathrm{P}^{*}}{\mathrm{~A}_{\mathrm{eq}}}\left[1+\frac{\mathrm{e}}{2} \sec \left(\frac{\mathrm{L}_{\text {buckling }}}{2 \mathrm{r}_{\text {layer }}} \sqrt{\frac{\mathrm{P}^{*}}{\mathrm{E}_{\text {milayer }}}}\right)\right]=f_{c} \\
\mathrm{r}_{\text {layer }}=\sqrt{\mathrm{I}_{\text {layer }} / \mathrm{A}_{\text {eq }}}
\end{gathered}
$$

The failure of the panel due to combined flexion-compression occurs when stress acting at the outer fiber of the mortar layer reaches the mortar compressive strength $f_{\mathrm{c}}$. Therefore, the maximum load $\left(P_{\max }\right)$ resisted by the panel in this case is obtained by solving iteratively [3] for $\sigma_{\max }=f_{\mathrm{c}}$.

\subsubsection{Failure due to lateral instability}

The failure due to lateral instability occurs when the lateral displacement at the center of the panel [2] equals half the displacement required to produce the buckling of the steel connectors. This is mathematically modeled in [5], in which $k_{1}$ and $k_{2}$ are coefficients that represent the bordering condition for each connector and for the whole panel, respectively. Such coefficients range from 0.5 , for pinned ends, and 1.0, for fixed ends. The coefficient $k_{3}$ (ranging from 0.0 to 1.0 ) takes into account the lateral restriction introduced by the EPS and the steel connectors whereas $\mathrm{L}_{\mathrm{c}}, \varphi_{\mathrm{c}}, n_{\mathrm{c} \text { secc }}$ represent the length, the diameter and the number of steel connectors per horizontal row. The maximum load resisted by the panel in this case is calculated through [6], which was obtained after isolating $P^{*}{ }_{\text {max }}$ in [5].

$$
\begin{gathered}
\mathrm{k}_{3} \mathrm{e}\left[\sec \left(\frac{\mathrm{k}_{2} \mathrm{~L}_{\text {buckling }}}{2} \sqrt{\frac{\mathrm{P}_{\text {max }}^{*} / 2}{\mathrm{E}_{\mathrm{m}} \mathrm{I}_{\text {layer }}}}\right)-1\right]=\left(\frac{1}{2}\right) \frac{\mathrm{n}_{\mathrm{c}, \mathrm{sec}} \pi^{2} \varphi_{\mathrm{c}}^{2}}{16 \mathrm{k}_{1}^{2} \mathrm{~L}_{\mathrm{c}}} \\
\mathrm{P}_{\max }^{*}=\frac{8 \mathrm{E}_{\mathrm{m}} \mathrm{I}_{\text {layer }}}{\mathrm{k}_{2}^{2} \mathrm{~L}_{\text {buckling }}^{2}}\left[\operatorname{acos}\left(\frac{1}{1+\frac{\mathrm{n}_{\mathrm{c}, \mathrm{sec}} \pi^{2} \varphi_{\mathrm{c}}^{2}}{32 \mathrm{e}_{3} \mathrm{k}_{1}^{2} \mathrm{~L}_{\mathrm{c}}}}\right)\right]^{2}
\end{gathered}
$$

\subsection{Small-scale panels}

The maximum load resisted by the small-scale panels tested in the first experimental program is estimated through the formulation deducted in sections 4.1.1 and 4.1.2 considering the mechanical properties and the geometrical characteristics already described. The estimation of the maximum load resisted by panels SC8, SC9 and SC10 was conducted considering the thinnest average mortar layer (15 $\mathrm{mm}$ ) since it represents the most unfavorable condition. The contribution of the thicker mortar layer $(25 \mathrm{~mm})$ is calculated indirectly though balance of forces and moments in the whole cross section.

For the rest of the panels analyzed, a symmetric stress distribution is assumed since both mortar layers have the same thickness. In this case, the maximum load is obtained by multiplying the load resisted by a single mortar 
layer (calculated with [3] and [6] by 2. It is important to remark that the elasticity modulus used was obtained using the formulation proposed in the EHE-08. (18)

Table 3 presented previously shows the maximum loads estimated for the panels. According to the results, the panels $\mathrm{SC} 1, \mathrm{SC} 2, \mathrm{SC} 11$ and $\mathrm{SC} 12$ are the only ones to present a failure due to combined flexion-compression. For the rest of the panels, failure occurs due to lateral instability. The correlation coefficient between the experimental results and the analytical estimation was of 0.91 . This correlation coefficient may be considered high given the natural variability that affects the experimental results. Therefore, the analytical formulation using the equations proposed in this paper was capable of simulating the structural behavior of the small-scale panels. It allowed the indirect estimation of the maximum load resisted as well as the identification of the different failure mechanisms that may happen.

Such observation becomes clear if the maximum loads (measured and estimated) are plotted depending on the length of the steel connectors, as shown in Figure 8. This figure shows that the theoretical curve fits well the majority of the experimental results regardless if the failure happens due to combined flexion-compression [3] or due to lateral instability [ 6]. The coefficient $k_{1}$ for the border condition of the connector is assumed equal to 0.68 for all curves, thus marking an intermediate condition between fixed and pinned ends. The coefficient $k_{2}$ for the border condition of the panel is assumed equal to 0.58 , which approaches the situation of fixed ends.

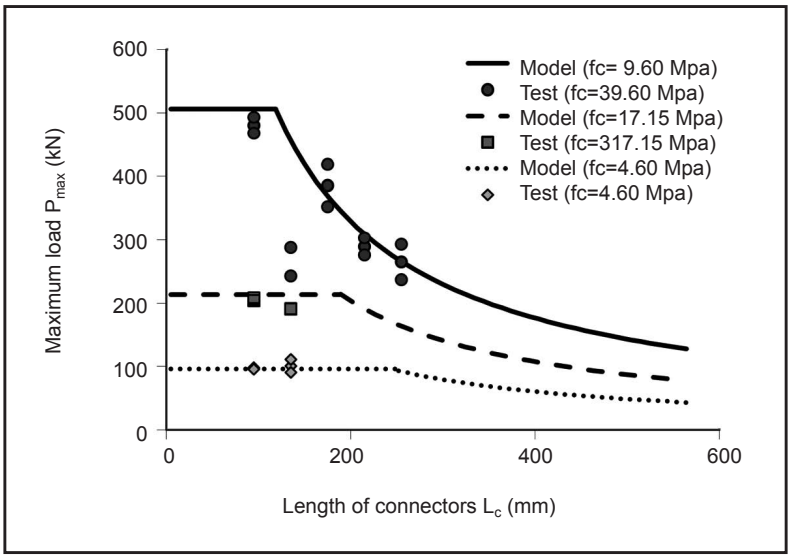

Figure 8. Maximum loads (measured and estimated) depending on the length of the steel connectors for small-scale panels.

The horizontal branch of the theoretical curves shows the cases of panels with the failure due to combined flexioncompression in which the maximum load is constant. On the other hand, the length of the connectors affect considerably the maximum load resisted in case of failure due to lateral instability. As observed in the experimental results, the increase of the panel thickness (length of connectors) produces a considerable decrease of the maximum load. In addition to that, the theoretical results show that the reduction of the mortar compressive strength lead to a significant reduction of the maximum load and an increase of the limit length that marks the transition from one failure mechanism to the other. This occurs because the mortar compressive strength affects more the resistance to combined flexion-compression than the resistance to lateral instability.

\subsection{Slender panels}

Figure 9 shows the graph of the experimental and the theoretical results in terms of the maximum load and the length of the connectors for slender panels. The same coefficients $k_{1}$ and $k_{2}$ used in the previous section were applied. Similarly to the observed for the small-scale panels, the theoretical curves fit the experimental results. This indicates the high representativeness of the analytical model that was able to reproduce the experimental results with the same parameter and despite the scale change of the specimens.

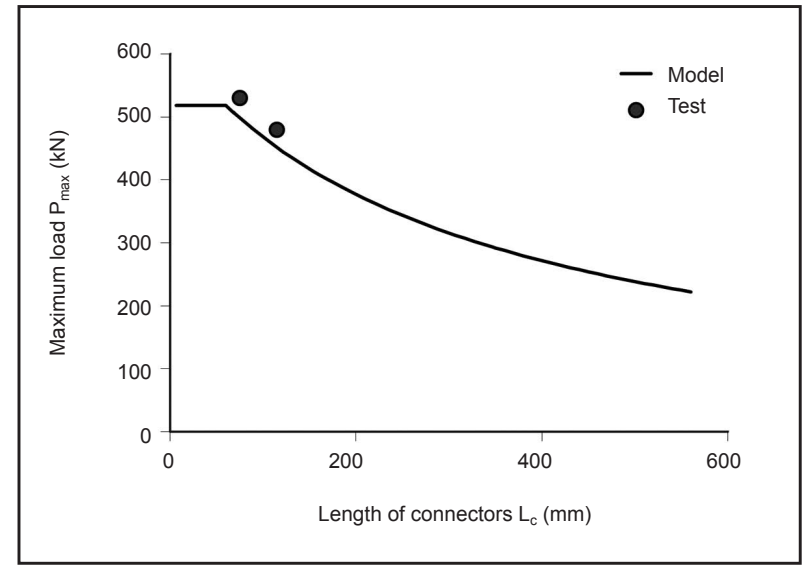

Figure 9. Maximum loads (measured and estimated) depending on the length of the steel connectors for slender panels.

\section{PARAMETRIC STUDY}

Given the good results obtained with Eq. [3] and [6], several aspects that may affect the structural behavior and the maximum load resisted by the panels were analyzed. For that, panels with characteristics and geometrical properties similar to that of the small-scale panels were considered.

Figure 10.a shows how the position of the reinforcing mesh in the mortar layer may affect the maximum load depending on the length of the connectors. The analysis 
to obtain the curves was performed for panels with the same material properties, mortar layer thickness, width and height as panel SC11. Two diameters were considered for the steel connectors: $3.4 \mathrm{~mm}$ and $5.0 \mathrm{~mm}$. The results indicate that the most unfavorable conditions occur as the reinforcing mesh approaches de inner face of the mortar layer whereas the most favorable condition occurs for a mesh centered in the mortar layer.

Such differences are more evident as the diameter of the bars used to compose the mesh increases. If the reinforcement is not centered, meshes with thicker bars dislocate more the gravity centerline of the mortar layer thus generating bigger eccentricities than meshes with thinner bars. In this context, the reduction on the resistant capacity caused by the increase of diameter may exceed the beneficial effect of increasing the reinforcement rate. Ultimately, the use of more reinforced panels may produce a significant reduction on the maximum load resisted.

The influence of the thickness of the mortar layer over the maximum load resisted by the panels is presented in Figure 10.b for panels with the same material properties, reinforcement distribution, EPS thickness, width and height as panel SC17. This figure shows that the increase of the diameter of the mortar layer leads to an increase of the maximum load estimated for the failure due to combined flexion-compression and due to lateral instability.

Figure 11.a shows the maximum load depending on the length and the number of connectors used per level for panels with the same material properties, connector diameter, height, width and thickness of mortar layer as panel SC3 (see Table 1). Analogously, Figure 11.b presents a similar graph depending on the diameter of the 2 connectors used per row.

It is clear that if the failure of the panel happens due to lateral instability, the maximum load resisted decreases with the reduction of the diameter or the number of connectors per row. However, no influence is observed if the failure happens due to the combined flexion-compression, which presents the same maximum load despite of the changes performed in the connectors. This indicates that, in case the failure is caused by lateral instability, to improve the maximum load resisted it is advisable to increase the number or the diameter of connector. On the contrary, in case the failure is caused by combined flexioncompression, it would be better to change the thickness of the mortar layer or its material properties.

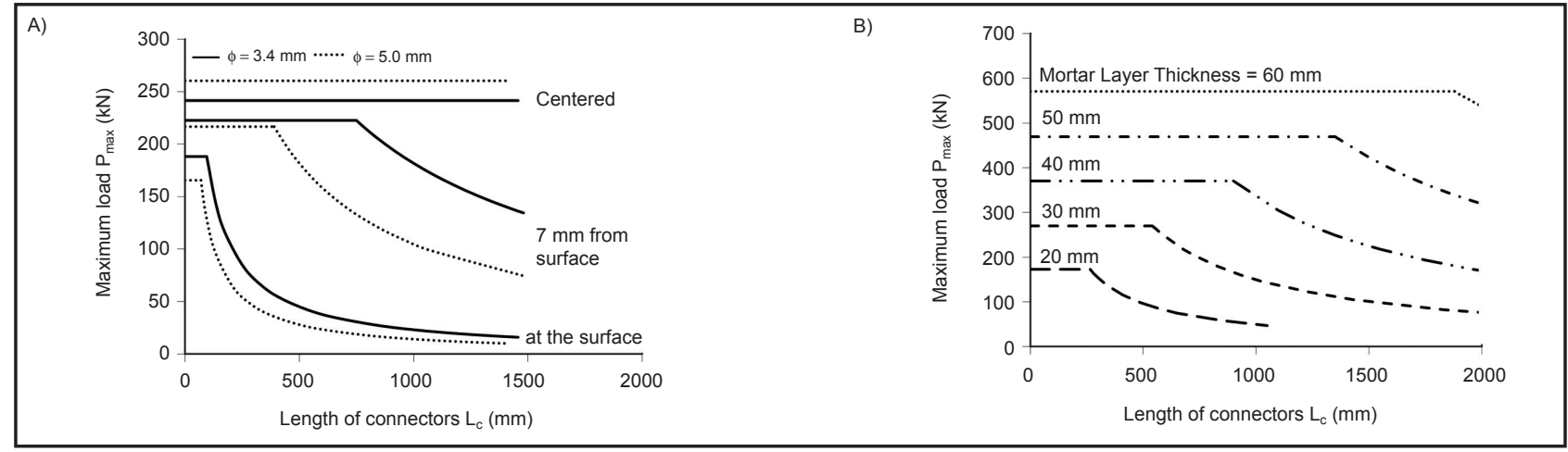

Figure 10. Maximum load depending on: a) the position of the center of gravity of the reinforcing mesh cast in the mortar layer and b) the thickness of the mortar layer

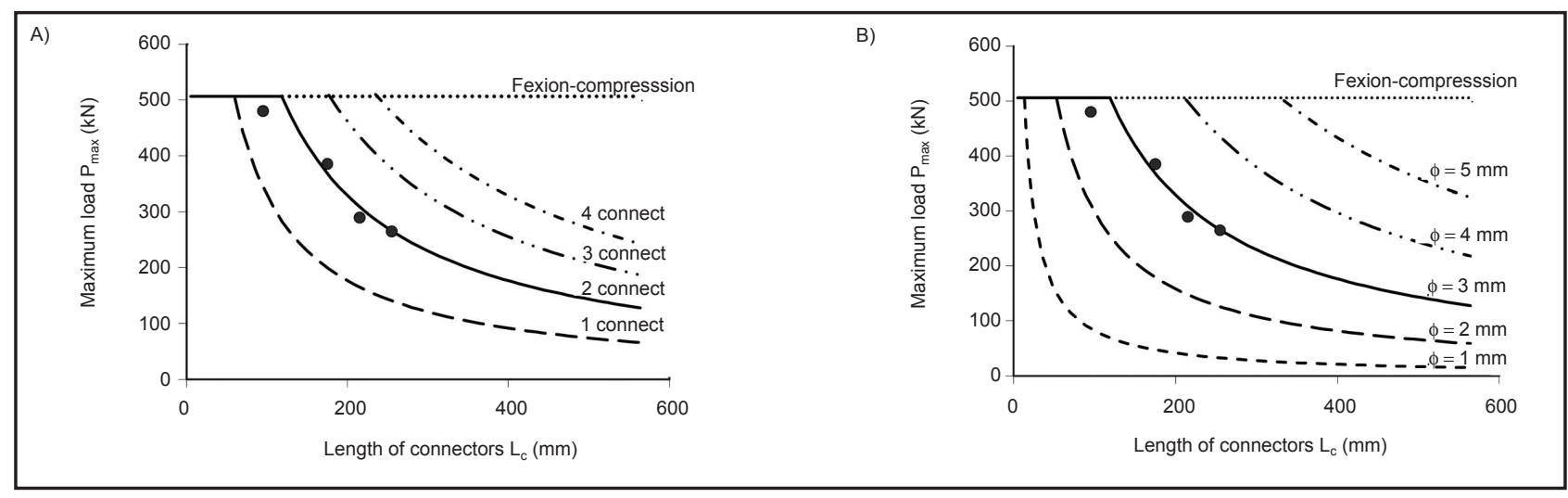

Figure 11. Maximum load depending on: a) the number of connectors with $3 \mathrm{~mm}$ of diameter used per level b) the diameter of the 2 connectors used per row 


\section{CONCLUSIONS}

The results obtained with small-scale and slender panels illustrate the structural behavior of the sandwich panels expected in practice. Despite the limited number of tests and repetitions in some cases, the results indicate that the compressive strength of the mortar and the thickness of the panels (length of connectors) are the main aspects that affect the maximum load resisted by the panels. Such load increases with the increase of the compressive strength and with the reduction of the panel thickness. All these observations are in good agreement with the results estimated with the analytical formulation proposed in this paper.

Such formulation differentiates between two possible failure mechanisms: 1 ) due to the combined flexion-compression or 2) due to the lateral instability of the mortar layer. For panels with small height, thin EPS (short steel connectors) or less resistant mortar the first failure mechanism predominates. The parametric study performed with the new formulation proposed shows that the increase of the number or of the diameter of the steel connectors increases the maximum load due to the lateral instability. On the other hand, the increase of the thickness of the mortar layer produces a consequent increase of the maximum load estimated for both failure mechanisms.

It was found that the resistance of the panels is maximized if the reinforcing mesh is centered at the mortar layer. Any other position dislocates the gravity centerline of the mortar layer thus generating an eccentricity that reduces the global normal load resisted. If the position of the reinforcing mesh is not centered in the mortar layer, a special care should be taken to select the diameter of the bars used. In this case, the use of meshes with thicker bars may have an adverse effect, producing the reduction of the maximum load resisted by the panel.

\section{BIBLIOGRAFÍA / BIBLIOGRAPHY}

(1) Carbonari, G.; Cavalaro, S. H. P.; Cansario, M.; Aguado, A.: "Flexural behaviour of light-weight sandwich panels composed by concrete and EPS". Constr. Build. Mater. (2012), 35, 792-799. http://dx.doi.org/10.1016/j.conbuildmat.2012.04.080

(2) Einea, P. E. A.; Salmon, D. C.; Fogarasi, G. J.; Culp, T. D.; Tadros, M. K.: "State-of-the-art of precast concrete sandwich panels". PCI J. November-December 1991, (1991), 78-98.

(3) Papanicolaou, C. G.; Triantafillou, T. C.: "Minimum cost design of concrete sandwich panels made of HPC faces and PAC core: the case of in-plane loading". Structural Concrete (Journal of the fib). 5, 1, (2002), 11-27.

(4) Reis, E. M.; Rizkalla, S. H.: "Material characteristics of 3-D FRP sandwich panels". Constr. Build. Mat. 22, 6, (2008), 1009-1018. doi: IO. $1016 /$ j.conbuildmat.2007.03.023

(5) Benayoune, A.; Samad, A. A. A.; Trikha, D. N.; Ali, A. A. A, Ellinna, S. H. M.: "Flexural behavior of pre-cast concrete sandwich composite panel - Experimental and theoretical investigations". Constr. Build. Mat. 22, 4, (2008), 580-592. doi:10.1016/j.conbuildmat.2006.11.023

(6) Bush, T. D.; Stine, G. L.: "Flexural behavior of composite precast concrete sandwich panels with continuous truss elements". PCI J. March-April, (1994), 112-121.

(7) Attard, M. M.; Hunt, G. W.: "Sandwich column buckling - A hyperelastic formulation". Int. J. Solid. Struct. 45, 21, (2008a), 5540-5555.

(8) Attard, M. M.; Hunt, G. W.: "Column buckling with shear deformations-A hyperelastic formulation". Int. J. Solid. Struct. 45, 14-15, (2008b), 4322-4339.

(9) Pokharel, N.; Mahendran, M.: "Experimental investigation and design of sandwich panels subject to local buckling effects". J. Constr. Steel. Res.. 59, 12, (2003), 1533-1552.

(10) Pokharel, N.; Mahendran, M.: "Finite element analysis and design of sandwich panels subject to local buckling effects". Thin-Walled Struc.t. 42, 4, (2004), 589-611.

(11) Mousa, M. A.; Uddin, N.: "Global buckling of composite structural insulated wall panels". Mater. Des.. 32, 2, (2011), 766-772.

(12) ACI Committee 318: "Building Code Requirements for Reinforced Concrete (ACI 318-89)". American Concrete Institute, (1989).

(13) Benayoune A.; Samad A. A. A.; Trikha D. N.; Ali A. A. A.; Ashrabov A. A.: "Structural behaviour of eccentrically loaded precast sandwich panels". Constr. Build. Mat.. 20, 9, (2006),713-724.doi:10.1016/j.conbuildmat.2005.02.002

(14) Benayoune, A.; Samad, A.A.A.; Abang Ali, A.A.; Trikha, D.N. "Response of Pre-cast Reinforced Composite Sandwich Panels to Axial Loading". Constr. Build. Mater.. 21, 3, (2007), 677-685. doi:10.1016/j.conbuildmat.2005.12.011

(15) Cansario, M. M.: "Sistema constructivo de paneles aligerados con poliestireno expandido y malla electrosoldada espacial: estudio estructural y optimización". PhD Dissertation. Universidad Politécnica de Cataluña, Barcelona, Spain, (2005)

(16) Shutt, C. A.: "Report Codifies, Details Sandwich Wall Panels". ASCENT 1997. Spring, (1997), 28-33.

(17) Gere, J. M.; Goodno, B. J.: "Mechanics Of Materials". 7th ed, Cengage-Engineering. ISBN 0495438073, (2008).

(18) EHE: "Instrucción de hormigón estructural". Ministerio de Fomento de España. Madrid, (2008). 